\title{
VARIATIONS IN SOME ANTHROPOMETRICAL PARAMETERS OF THE WOMEN WITH THE DIFFERENT IRIS COLOR IN LATVIA
}

\author{
Dzintra Kažoka, Jānis Vētra \\ Riga Stradiņš University, Institute of Anatomy and Anthropology, Riga
}

\begin{abstract}
The aim of this study was to confirm the variations between the women with the different iris color in their anthropometrical parameters. The sample of subjects consisted of 873 women from Latvia. Twelve anthropometrical measurements were taken, all of which covered the area of the longitudinal, transversal, circular dimensionality and the subcutaneous fatty tissue. The differences between the anthropometrical parameters were determined by means of the t-test for independent samples.

In $51.8 \%$ the iris color was blue as the most prevalent color, and in $7.1 \%$ the color was brown as the least prevalent color. In many of the parameters were found intra-group differences, which signaled that the group was heterogeneous in terms of the evaluated characteristics. The results showed that there were some statistically significant differences of the anthropometrical parameters between the women with the different iris color. Further studies are recommended to investigate the probable associations.
\end{abstract}

Key words: anthropometrics, women, iris color, variations, comparison

\section{INTRODUCTION}

Population variations in the body size represent one of the most important parameters in the study of the ongoing evolution of man [1, 2 ]. There is considerable evidence indicating that the human variation in the body size is the result of the interaction of environmental and genetic factors at both the developmental and adult stages [16]. 
The eye color or, more accurately, the iris color is one of the most obvious physical characteristics of a person. Pigmentation, including the eye color, is one of the major racial and diagnostic features in anthropological studies and it is used to characterize differences between populations. The studies carried out by certain authors have shown that there may be some associations between the eye color and the constitutional type $[3,5]$. The study of the normal pigmentation variation in humans is more recent and has been investigated by anthropologists, medical scientists and by researchers for the prediction of visible phenotypes to be used as an investigative tool [7].

The aim of the study was to confirm some variations between the women with the different iris color in their anthropometrical parameters.

\section{MATERIAL AND METHODS}

A total of 873 women took part in the data collection between 2001 and 2005 in Latvia. All of them were healthy at the time of investigation.

The body height was used to evaluate longitudinal dimensionality. For all the women the body weight was measured. The following parameters were used to evaluate the transversal dimensionality: biacromial width, the waist width and the bicristal width. The following parameters were used to evaluate the subcutaneous fatty tissue: biceps and triceps skinfolds, subscapular and suprailiac skinfolds. The chest, waist and hip circumferences were used to evaluate circular dimensionality.

All the anthropometrical measurements were carried out according to the methodological recommendations by R. Martin and K. Saller [13]. The anthropometrical measurements were measured by the author of this study together with the medical nurses of the anthropology unit of the Institute of Anatomy and Anthropology (IAA). The Swiss company"s "Siber-Hegner and Co" anthropometric set, the skinfold caliper, the steel measuring tape and the same electronic weight scales were used during the investigation.

The visual assessment of the eye color was carried out using the traditional scale of Martin, based on 16 ocular prostheses. The iris color was determined according to the Martin/Schulz's table of the iris-color. The four-category grading system (groups of the iris color) was used to determine the variations in some anthropometrical parameters: blue (group I), grey (group II), green (group III) and brown (group IV). 
The data were entered into the SPSS Statistics program 17.0. The basic descriptive parameters were calculated for all the results: the arithmetic means, the standard deviation, the minimum value (min), the maximum value $(\max )$ and the range. The differences between the anthropometrical measurements of the women were examined using the t-test for independent samples. The level of significance was defined as $\mathrm{p}<0.05 ; \mathrm{p}<0.01$ and $\mathrm{p}<0.001$.

\section{RESULTS}

The sample of the subjects consisted of 873 women. The mean age of the participants was $28.78 \pm 13.76$ years. In $51.8 \%$ the iris color was blue as the most prevalent color, and in $7.1 \%$ the color was brown as the least prevalent color. The prevalence of grey and green iris color was $16.2 \%$ and $25.0 \%$, respectively. The descriptive parameters for anthropometric characteristics of women with the different iris color were presented in Table 1 and Table 2.

The differences between the mean values for the anthropometrical parameters were shown in Table 3. The results for the mean body height for the women showed that the difference between the shortest $(164.34 \pm 7.34 \mathrm{~cm}$ for the brown iris color or group IV) and the tallest body height ( $165.53 \pm 6.36 \mathrm{~cm}$ for the grey iris color or group II) was $1.19 \mathrm{~cm}$. The differences between the minimum and the maximum values for the anthropometric measures were in accordance with the displayed differences in the body height. The greatest difference between the lowest $(62.63 \pm 11.78 \mathrm{~kg}$ for the green iris color or group III) and the highest $(65.81 \pm 14.75 \mathrm{~kg}$ for the brown iris color or group IV) the mean value for the body weight was $3.18 \mathrm{~kg}$. The results showed that no statistically significant differences were noted for the mean values of both mentioned anthropometrical parameters in the compared iris color groups. 
Table 1. The descriptive parameters for anthropometric characteristics of the women with the blue and grey iris color

\begin{tabular}{|l|c|c|c|c|c|}
\hline I group - blue iris color $(\mathrm{n}=452)$ & Range & M & SD & $\min$ & $\max$ \\
\hline Body height, cm & 32.80 & 165.31 & 6.59 & 149.50 & 182.30 \\
\hline Body weight, $\mathrm{kg}$ & 66.30 & 62.93 & 11.80 & 40.30 & 106.60 \\
\hline Biacromial width, cm & 11.40 & 35.49 & 1.84 & 28.50 & 39.90 \\
\hline Waist width, cm & 17.90 & 26.08 & 2.41 & 20.50 & 38.40 \\
\hline Bicristal width, cm & 18.90 & 29.27 & 2.70 & 22.00 & 40.90 \\
\hline Chest circumference, cm & 65.80 & 85.30 & 7.87 & 57.00 & 122.80 \\
\hline Waist circumference, cm & 66.00 & 70.59 & 10.47 & 52.50 & 118.50 \\
\hline Hip circumference, cm & 61.10 & 95.58 & 9.39 & 77.00 & 138.10 \\
\hline Biceps skinfold, mm & 20.00 & 7.24 & 2.76 & 2.00 & 22.00 \\
\hline Triceps skinfold, mm & 27.40 & 13.09 & 3.90 & 3.40 & 30.80 \\
\hline Subscapular skinfold, mm & 29.60 & 14.09 & 5.87 & 4.80 & 34.40 \\
\hline Suprailiac skinfold, mm & 31.20 & 14.70 & 5.71 & 3.80 & 35.00 \\
\hline II group - grey iris color $(\mathrm{n}=141)$ & Range & M & SD & min & max \\
\hline Body height, cm & 34.50 & 165.53 & 6.36 & 147.50 & 182.00 \\
\hline Body weight, kg & 65.30 & 64.93 & 12.83 & 45.40 & 110.70 \\
\hline Biacromial width, cm & 11.80 & 35.86 & 2.00 & 28.50 & 40.30 \\
\hline Waist width, cm & 15.90 & 26.99 & 2.83 & 22.10 & 38.00 \\
\hline Bicristal width, cm & 17.40 & 30.45 & 3.18 & 25.50 & 42.90 \\
\hline Chest circumference, cm & 42.40 & 87.61 & 8.51 & 73.10 & 115.50 \\
\hline Waist circumference, cm & 51.00 & 73.38 & 11.39 & 56.00 & 107.00 \\
\hline Hip circumference, cm & 80.00 & 97.63 & 10.54 & 57.00 & 137.00 \\
\hline Biceps skinfold, mm & 18.70 & 7.43 & 3.06 & 2.60 & 21.30 \\
\hline Triceps skinfold, mm & 25.30 & 13.30 & 4.64 & 5.00 & 30.30 \\
\hline Subscapular skinfold, mm & 29.20 & 14.61 & 6.09 & 4.80 & 34.00 \\
\hline Suprailiac skinfold, mm & 32.40 & 15.14 & 6.20 & 5.00 & 37.40 \\
\hline
\end{tabular}

$\mathrm{n}$ - number of women; $\mathrm{M}$ - mean; SD - standard deviation; min - minimum; max maximum 
Table 2. The descriptive parameters for anthropometric characteristics of the women with the green and brown iris color

\begin{tabular}{|l|c|c|c|c|c|}
\hline III group - green iris color $(\mathrm{n}=218)$ & Range & M & SD & min & max \\
\hline Body height, $\mathrm{cm}$ & 35.80 & 164.62 & 6.62 & 145.30 & 181.10 \\
\hline Body weight, $\mathrm{kg}$ & 79.10 & 62.63 & 11.78 & 41.00 & 120.10 \\
\hline Biacromial width, cm & 23.70 & 35.71 & 2.23 & 29.70 & 53.40 \\
\hline Waist width, cm & 16.70 & 26.39 & 2.53 & 20.90 & 37.60 \\
\hline Bicristal width, cm & 16.50 & 29.67 & 2.83 & 24.80 & 41.30 \\
\hline Chest circumference, cm & 43.00 & 86.27 & 7.65 & 74.20 & 117.20 \\
\hline Waist circumference, cm & 64.30 & 72.32 & 11.32 & 56.00 & 120.30 \\
\hline Hip circumference, cm & 52.20 & 96.48 & 9.61 & 81.00 & 133.20 \\
\hline Biceps skinfold, mm & 19.00 & 7.39 & 2.93 & 2.00 & 21.00 \\
\hline Triceps skinfold, mm & 27.20 & 12.81 & 4.07 & 2.80 & 30.00 \\
\hline Subscapular skinfold, mm & 30.20 & 14.27 & 5.50 & 4.80 & 35.00 \\
\hline Suprailiac skinfold, mm & 32.00 & 14.63 & 5.66 & 4.00 & 36.00 \\
\hline IV group - brown iris color $(\mathrm{n}=62)$ & Range & M & SD & Min & max \\
\hline Body height, cm & 29.90 & 164.34 & 7.34 & 150.70 & 180.60 \\
\hline Body weight, kg & 83.10 & 65.81 & 14.75 & 41.00 & 124.10 \\
\hline Biacromial width, cm & 10.40 & 35.91 & 1.76 & 29.10 & 39.50 \\
\hline Waist width, cm & 12.20 & 26.66 & 2.40 & 21.40 & 33.60 \\
\hline Bicristal width, cm & 12.90 & 29.87 & 2.66 & 23.90 & 36.80 \\
\hline Chest circumference, cm & 51.80 & 88.06 & 9.41 & 74.20 & 126.00 \\
\hline Waist circumference, cm & 80.00 & 75.56 & 14.72 & 56.00 & 136.00 \\
\hline Hip circumference, cm & 64.30 & 98.25 & 11.21 & 81.50 & 145.80 \\
\hline Biceps skinfold, mm & 19.80 & 8.15 & 3.76 & 3.40 & 23.20 \\
\hline Triceps skinfold, mm & 16.00 & 13.28 & 3.86 & 5.20 & 21.20 \\
\hline Subscapular skinfold, mm & 27.20 & 15.31 & 5.88 & 6.80 & 34.00 \\
\hline Suprailiac skinfold, mm & 27.60 & 16.37 & 6.98 & 7.00 & 34.60 \\
\hline
\end{tabular}

$\mathrm{n}$ - number of women; $\mathrm{M}$ - mean; SD - standard deviation; min - minimum; max maximum 


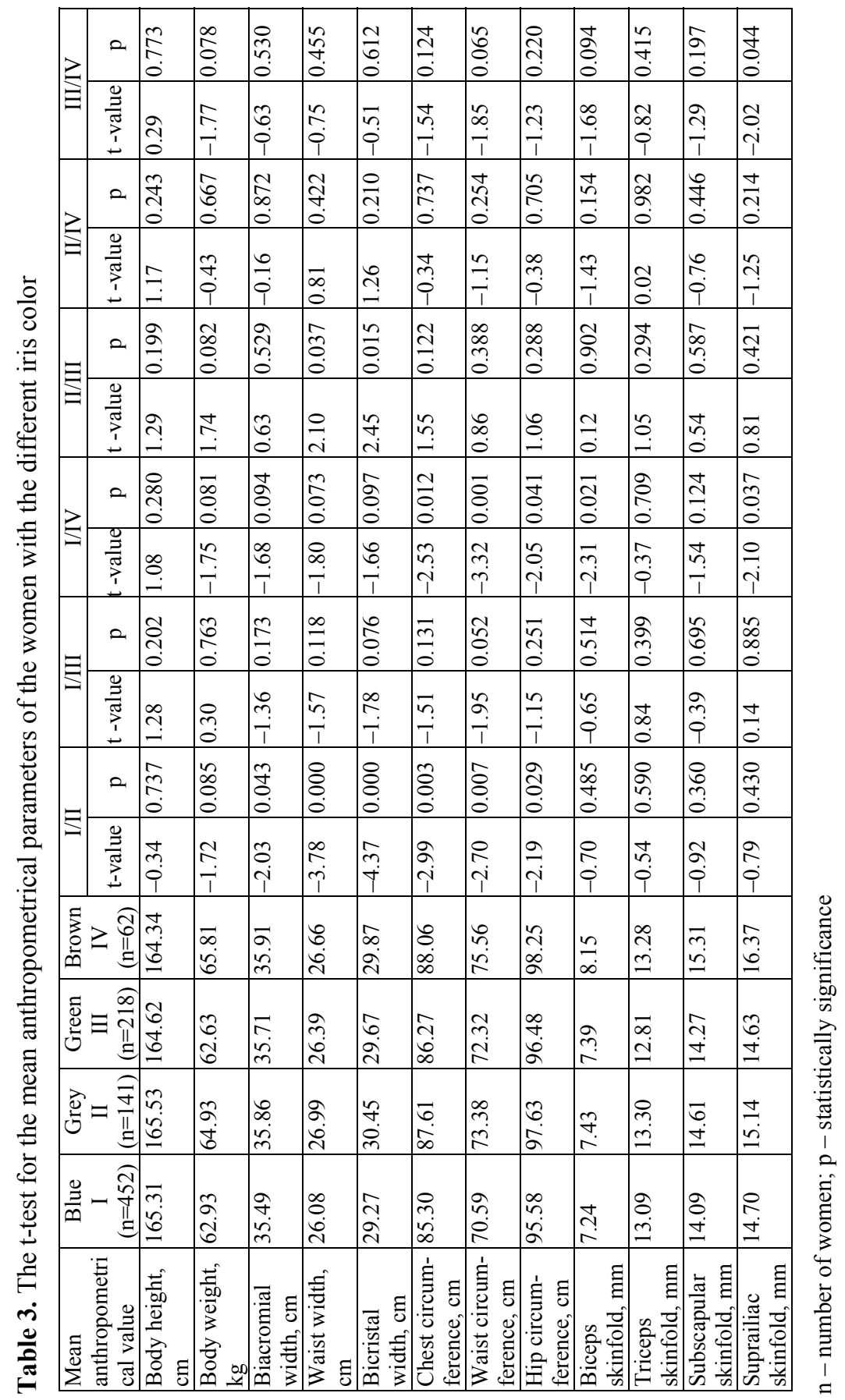


The values for the mean parameters for the transversal dimensionality of the skeleton for the women indicated that there were small numerical differences between the lowest and the highest mean values for all the measured parameters. The maximum mean value for the biacromial width $(35.91 \pm 1.76 \mathrm{~cm})$ was noted for the women with the brown iris color or in group IV. In group II or for the women with grey iris color were the highest mean values for the waist width and the bicristal width $(26.99 \pm 2.83 \mathrm{~cm}$ and $30.45 \pm 3.18 \mathrm{~cm})$. Statistically significant differences were found between the mean values of the waist width and the bicristal width for the women with the blue and grey (group I and group II) iris color $(\mathrm{p}<0.001)$.

The studied variables for circular dimensionality for the women indicated a different range. The minimum mean values for the chest, the waist and the hip circumferences $(85.30 \pm 7.87 \mathrm{~cm} ; 70.59 \pm 10.47 \mathrm{~cm}$ and $95.58 \pm 9.39 \mathrm{~cm}$ ) were noted for the women with the blue iris color or in group I. The maximum mean values of the mentioned parameters $(88.06 \pm 9.41 \mathrm{~cm} ; 75.56 \pm 14.72 \mathrm{~cm}$ and $98.25 \pm 11.21 \mathrm{~cm})$ were indicated for the women with the brown iris color or in group IV. The differences were statistically significant between both compared groups $(\mathrm{p}<0.05$ and $\mathrm{p}<0.001$ ).

The differences between the minimum and the maximum values for skinfolds indicated great ranges for the measured points. Great intragroup differences were noted. The minimum mean values for biceps skinfold $(7.24 \pm 2.76 \mathrm{~mm})$ and the subscapular skinfold $(14.09 \pm 5.87 \mathrm{~mm})$ were found for the women with the blue iris color or in group I, but the maximum mean values of these parameters $(8.15 \pm 3.76 \mathrm{~mm}$ and $15.31 \pm 5.88 \mathrm{~mm}$ ) were noted for the women with the brown iris color or in group IV. Statistically significant differences between the mean values of the mentioned groups were described only for the biceps skinfold $(\mathrm{p}<0.05)$.

In group III or for the women with the green iris color the minimum mean values for triceps and suprailiac skinfolds $(12.81 \pm 4.07 \mathrm{~mm}$ and $14.63 \pm 5.66 \mathrm{~mm})$ were noted. The maximum mean value for the triceps skinfold $(13.30 \pm 4.64 \mathrm{~mm})$ was indicated for the women with the grey iris color or in group II, but the maximum mean value for the suprailiac skinfold $(16.37 \pm 6.98 \mathrm{~mm})$ was found for the women with the brown iris color or in group IV. The difference between the minimum and the 
maximum values for the suprailiac skinfold was statistically significant $(\mathrm{p}<0.05)$.

\section{DISCUSSION}

Eyes need not necessarily be regarded only as the physiological devices of sight, as the organs that receive information from the outside of the organism. Eyes certainly represent the structures that offer information about the present and the future behaviour [11]. Compared to the eyes of our closest relatives, human eyes are somewhat unusual in both their color and shape. There is some evidence of a relationship between the iris color and a variety of other factors. The eye color is also suspected for its role as a possible medicinal prognostic factor.

The study of the human iris color as a physical trait is based on the developmental biology, morphology, chemistry and the genetic determinants of the structure known as the iris [8]. The iris is a small connective tissue and the muscular structure of around $12 \mathrm{~mm}$ in diameter with a central opening called the pupil. It controls the amount of light entering the eye which is focused by the lens onto the retina so as to provide the sense of vision. It contracts in bright light making the pupil smaller and dilates in dark conditions making the pupil larger, which together with the source of the incident light can influence the perception of an individual's eye color and the iris pattern. In the brown iris there is an abundance of melanocytes and melanin in the anterior border layer and the stroma whereas in the blue iris these layers contain very little melanin [9].

The iris color can provide different information about an individual. These visible characteristics, which are generally called the texture of the iris, are unique to each subject. In addition to the changes with pathological conditions, the color of the iris can be a particularly useful indicator. The measurement of the iris color and its changes can be of great importance.

The color of the iris is affected by genetic and racial factors, and suggested as an independent factor in ocular conditions [6, 15]. This report is one of the few reports in the world in which the distribution of the iris color is studied in a population; nonetheless, the use of different definitions and measurement techniques for the iris colors makes 
comparisons with other reports difficult [14]. Variations may be due to genetic or environmental differences, or simply to chance. The presence of these differences dictates that the description of a single individual is not sufficient to describe an entire species' morphology, ecology, development or anything else. Instead, the description of many individuals taken together defines a range of the variation that encompasses the species. The variation in morphology between individuals is the most obvious kind of variation.

Determining the association between the iris color and different eye conditions can help us use the iris color as a predictive factor in some ocular variables and conditions [4]. The human iris has many other characteristic patterns that are not measured through an assessment of eye color and these will also be under strong genetic influence $[10,12]$, but remain to be fully investigated. For example, although the eye color is assumed to be fixed for adult life, there can be changes as individual ages or changes in disease states. The iris color can be affected by a variety of ocular disorders. It is suspected that the iris color may not remain constant throughout life.

On the basis of the results we can conclude that in Latvia the most prevalent color of the iris for women was blue. There were statistically significant differences between the women with the different iris color in some studied anthropometric parameters. In group II or for the women with the grey iris color statistically highest mean values were for waist width and bicristal width than the mean values of mentioned parameters for the women with the blue iris color or in group I. All the studied mean values for circular dimensionality were statistically significantly higher for the women with the brown iris color or in group IV than the mean values of circumferences for the women with the blue iris color or in group I.

It would be of interest to continue such a study to document the variations of some anthropometrical parameters of the women with the different iris color related to their geographical origin in Latvia.

\section{ACKNOWLEDGEMENTS}

This study was undertaken as a part of the investigation "Appreciation of the biological status of women in Latvia". It was funded by the European Union's Structural Funds for Scientific Research. In addition, 
aknowledgement is given to the following institutions: Riga Stradiňs University, the Institute of Anatomy and Anthropology, the Department of Anthropology and the Physics Department. The authors wish to thank the medical nurses of the anthropology unit for helping during anthropometrical measurements of women.

\section{REFERENCES}

1. Bogin, B. (1999) Patterns of Human Growth. $2^{\text {nd }}$ edition. Cambridge University Press, Cambridge.

2. Cameron N., Demerath E.W. (2002) Critical periods in human growth: relationship to chronic disease. Yearbook of Physical Anthropology, 45, 159-184.

3. Conrad K. (1963) Der Konstitutionstypus. Springer, Berlin.

4. Cumming R.G., Mitchell P., Lim R. (2000) Iris color and cataract: The blue mountains eye study. American Journal of Ophthalmology, 130, 237-238.

5. Damon A. (1970) Constitutional medicine. In: Von Mering, O., Kasdan, L. (eds.): Anthropology and the Behavioral and Health Science. University of Pitsburg Press, Pitsburg, 179-205.

6. Frost P. (2006) European hair and eye color: a case of frequency dependent sexual selection? Evolution and Human Behavior, 27, 85103.

7. Frudakis T., Thomas M., Gaskin Z., Venkateswarlu K., Chandra K.S., Ginjupalli S., Gunturi S., Natrajan S., Ponnuswamy V.K., Ponnuswamy K.N. (2003) Sequences associated with human iris pigmentation. Genetics, 165, 2071-2083.

8. Imesch P.D., Wallow I.H.L., Albert D.M. (1997) The color of the human eye: a review of morphologic correlates and of some conditions that affect iridial pigmentation. Survey of Ophthalmology, 41 (2), S117-S123.

9. Kobayashi H., Kohshima S. (1997) Unique morphology of the human eye. Nature, 387, 767-768.

10. Larsson M., Pedersen N.L. (2004) Genetic correlations among texture characteristics in the human iris. Molecular Vision, 10, 821-831.

11. Larsson M., Pedersen N.L., Stattin H. (2007) Associations between iris characteristics and personality in adulthood. Biological Psychology, 75, $165-175$. 
12. Larsson M., Pedersen N.L., Stattin H. (2003) Importance of genetic effects for characteristics of the human iris. Twin Research, 6 (3), 192200.

13. Martin R., Saller K. (1957) Lehrbuch der Anthropologie. Stuttgart, Fischer, Bd. I.

14. Seddon J.M., Sahagian C.R., Glynn R.J., Sperduto R.D., Gragouda E.S. (1990) Evaluation of an iris color classification system. Investigative Ophthalmology \& Visual Science, 31, 1592-1598.

15. Sulem P., Gudbjartsson D.F., Stacey S.N. et al. (2007) Genetic determinants of hair, eye and skin pigmentation in Europeans. Nature Genetics, 39, 1443-1452.

16. Tanner J.M. (1990) Growth as a mirror of conditions in society. In: Lindgren, G.W. (ed.): Growth as a mirror of conditions in society. Institute of Education Press, Stockholm, 9-48.

\section{Address for correspondence:}

Dzintra Kažoka

Riga Stradiņš University

Institute of Anatomy and Anthropology,

Kronvalda blv. 9, Riga, Latvia, LV-1010,

E-mail: dzintrakazoka@inbox.lv

dzintra.kazoka@rsu.lv 